\title{
Creating and Implementing a Vision For the School
}

By Edward W. Chance and Marilyn L. Grady

Administrators, confronted

by complex tasks, economic restrictions, and community concerns, need clear visions to guide their schools and staffs toward effective learning. How can they clarify and develop vision?

\section{$\mathrm{V}$}

isionary leadership is a prominent trait of high per forming administrators.

The U.S. Department of Education's Principal Selectio Guide (1987), states that "effective school leaders hav broad visions that are clear, active, ambitious, and perfo mance-oriented." The Guide further notes that effecti administrators "create conditions to help them realize the visions." Vision is the force, the dream toward which effe tive administrators strive in shaping their individu schools for success.

Definitions of vision vary. Manasse (1985) describ

Edward W. Chance is professor of education at the University of Oklahoma, Norman. Marilyn L. Grady is a professor of education at the University of

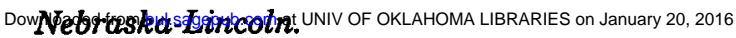


rision as "the development, transnission, and implementation of a lesirable future." Batsis (1987) dentified vision as more comprerensive than goals and objectives. shieve and Shoenheit (1987) indi:ated that " $\mathrm{A}$ vision is a blueprint of $i$ desired state. It is an image of a Jreferred condition that we work to ichieve in the future."

In a study of eight highly effective Jrincipals, Blumberg and Greenfield 1980) found that those principals who had vision created an environnent in which their personal values rovided a foundation for the school. Manasse (1982) indicated that effec- tive administrators have visions of schools that reflect established and entrenched publicly articulated values. These values were discussed and explained within the educational community.

Grady and LeSourd $(1988,1989)$ identify five dominant qualities of a leader with vision. Leaders with vision:

- Are guided and motivated by personal values

- Have an intense commitment to the achievement of goals that they identified as important for their organizations

- Develop a sense of common pur-

\section{igure 1}

onsiderations in Developing a Personal Vision

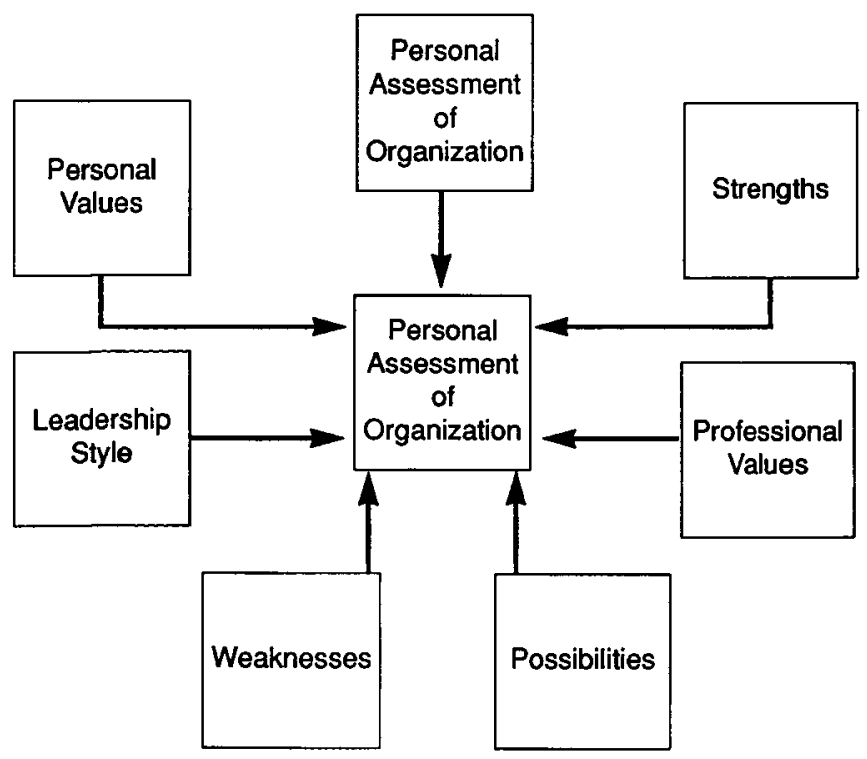


Figure 2

Considerations in Developing a Vision for a School

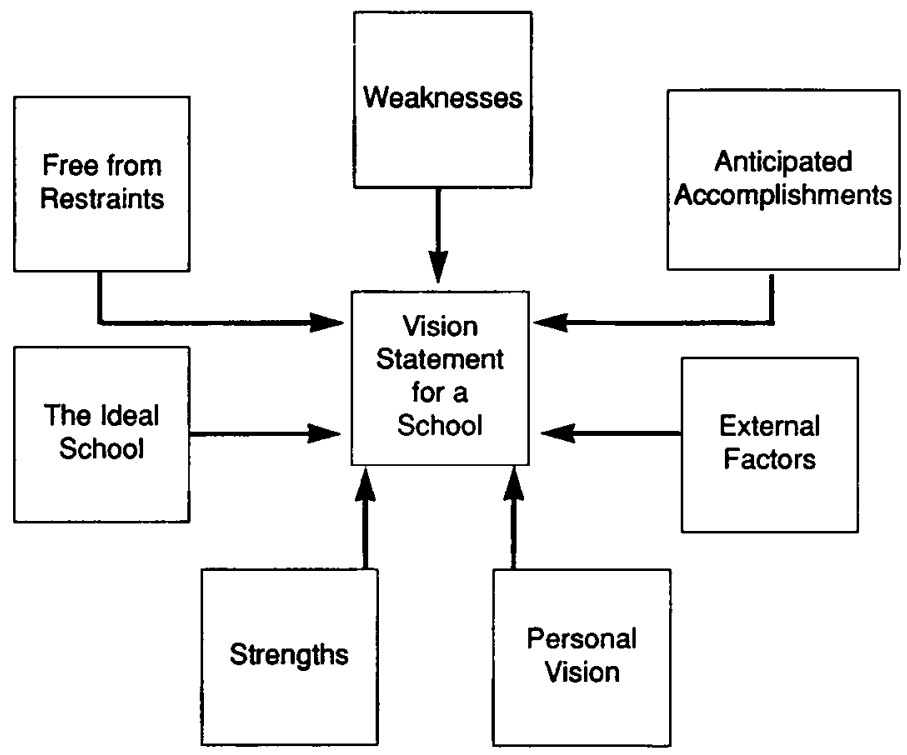

pose and direction among all members of their organizations

- Are organizational innovators

- Consistently focus on a future that represents something better. However one defines vision, it is intangible yet essential because it provides direction for an organization. Vision is a powerful force that guides, cajoles, directs, and facilitates accomplishment.

\section{Why Is Vision Important?}

A crucial aspect of leadership is the development of a vision that not only calls for excellence but estab- lishes an educational environmer and culture in which this can $b$ achieved. Administrators must b willing to ask the questions, "Wh: are we doing? Is it working? Can be done better?" and then listen the answers. Administrators wl are leaders must be able to mod and articulate their visions whi striving to actualize the organit tion they envision.

A vision unifies a school a increases the emotional support those in the organization (Litt and Fried, 1988). Individuals wit such an organization work toget to achieve the vision and beli 
their daily contributions are important in realizing the vision.

Vision guides the school's administrators, faculty, students, and support staff. Because expectations, goals, and purposes are clear, vision helps establish the climate for the school.

\section{How To Clarify/Develop a Vision}

Vision begins within the individual; it originates as a personal concept and reflects personal values, personal assessment of the organization, personal views of possibilities, and professional values. In developing a personal vision, administrafors might ask the following selfassessment questions:

What are my five greatest strengths?
- What are my five greatest weaknesses?

- What are three things I value most in my professional life?

- With which leadership style am I most comfortable?

- What are the most important things I want to accomplish in this school?

- How would I like to be remembered as an administrator?

- What do I want to prove as a leader?

Once these questions are answered, they can begin to formulate or clarify their vision. Figure 1 illustrates important considerations in developing a personal vision.

\section{A Vision for the School}

A second step in developing and

\section{Figure 3}

steps in Developing Vision and Sustaining a Vision for a School

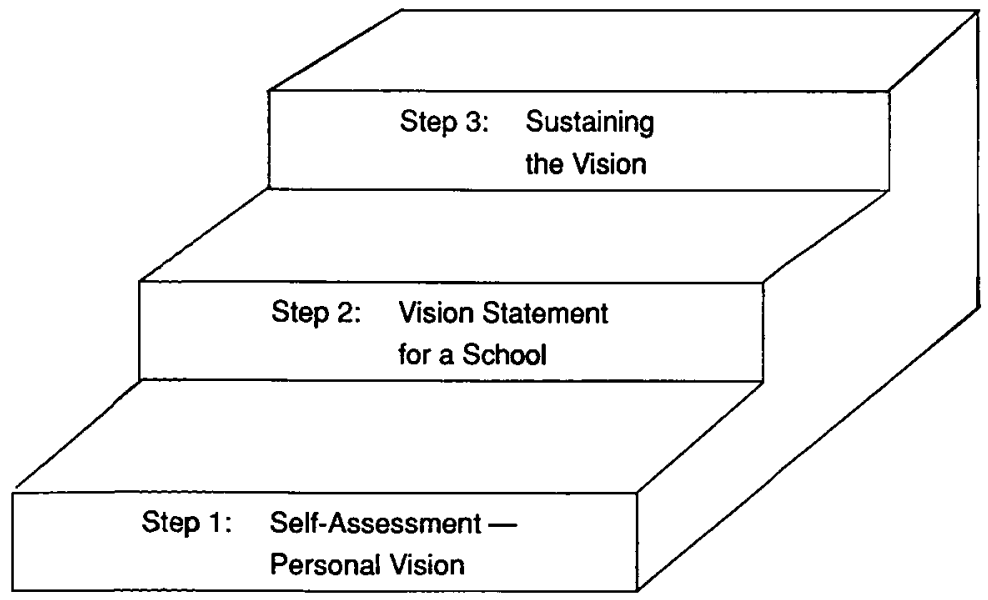


implementing vision is establishing a vision statement for the school. This is developed in much the same manner as the personal vision. Some of the questions that can be asked are:

- What are the strengths of this school?

- What are its weaknesses?

- What external factors help or hinder the proper functioning of this school?

- What is the existing relationship between the various components of the school?

Additional useful questions identified by Kouzes and Posner (1987) are:

- How would you like to change the world for yourself and your organization?

- If you could invent the future, what future would you invent for yourself and your organization?

- What does your ideal organization look like?

After answering these questions, knowledge of the organization can be used to facilitate the implementation of the vision statement. Next, long-term and short-term priorities should be identified and other organization members involved in clarifying the vision. Implementing the vision and identifying areas of responsibility are next. The leader's personal vision must be evident as a guiding force. Figure 2 presents issues to be considered in develop- ing a vision for the school.

\section{Sustaining the Vision}

Shieve and Shoenheit (1987) identified five distinct steps for attaining a vision: see it, own it, make this personal vision a public/ organizational one, develop strategies to achieve it, and begin acting on the vision. Involvement of others, selling the vision through effective communication, and utilizing resources wisely all facilitate implementation of the vision.

Effective administrators allocate funding, materials, and time in pursuit of the vision and systematically and judiciously utilize instructional management strategies, advantageous scheduling, recognition, and rewards to achieve the vision. Effective visionary leaders constantly pur sue a school climate that enhances learning and advances teacher pro ductivity.

Communication of the vision $i$ crucial. Others must know what th vision is and be able to articulat and publicize the vision in their ow way. The vision should be commun cated to everyone associated wit the school.

Administrators with vision e gage their staffs in decision makir and problem solving to shape orgar zational activities, teacher perfo mance, and student behavior an learning. This staff involvement $n$ 
only builds collegiality but exhibits what has been deemed organizationally important.

Challenges for School Leaders (AASA, 1988), identifies two important aspects that not only facilitate the implementation but assist in sustaining the vision.

The first aspect is to free administrators periodically from daily tasks to attend meaningful workshops or conferences, or to visit other schools that have been identified as effective.

The second suggestion is to allow the administrative staff to spend time in the summer on strategic planning. This planning could focus on how far the organization has progressed and how the school can continue to move toward the fulfillment of the vision.

If the vision is to be sustained, here must be an opportunity for enewal and an evaluation of prorammatic approaches. Figure 3 preents a model that includes the omponents that are critical to eveloping and sustaining a school's ision.

\section{onclusion}

ffective administrators who are structional leaders and utilize ared decision-making and teamilding activities posses vision. Sucssful administrators are more than

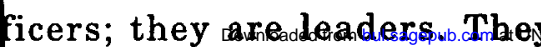

understand that without direction and purpose, school programs, facilities, and morale will deteriorate. To prevent this, administrators must set priorities and goals, involve others in decision making, continue their professional growth, and provide impetus and guidance to the school. They must also, as Barth (1988) states, believe in teachers, attribute much success to them, and not be afraid to admit that an administrator may not know everything and may need assistance. Simply put, the successful, effective administrator must develop, implement, and sustain the vision of not what the school should be but what the school will be.

The creation and development of a vision for the school should be an administrator's first priority. Vision provides only the destination. When a visionary leader collaborates with the stakeholders of the school, the trip can be an exciting and rewarding one.

\section{References}

Barth, R. S. "Principals, Teachers, and School Leadership." Phi Delta Kappan 9(1988).

Batsis, T. M. "Characteristics of Excellent Principals." Paper presented at the annual meeting of the National Catholic Educational Association, New Orleans, La., April 1987.

Blumberg, A., and Greenfield, W. The

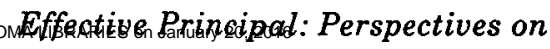


School Leadership. Boston: Allyn and Bacon, 1980.

Grady, M. L., and LeSourd, S. J. Principals' Attitudes Toward Visionary Leadership. A paper presented at the National Council of Professors of Educational Administration National Conference, Kalamazoo, Mich., August 1988.

Kouzes, J. M., and Posner, B. Z. The Leadership Challenge: How To Get Extraordinary Things Done in Organizations. San Francisco: JosseyBass, 1987.

LeSourd, S. J., and Grady, M. L. "Visionary Attributes in Principals' Description of Their Leadership." The High School Journal, 1989.

Littky, D., and Fried, R. "The Challenge To Make Good Schools Great."
- NEA Today, January 1988.

Manasse, A. L. "Effective Principals: Effective at What?" Principal, March 1982.

- "Vision and Leadership: Paying Attention to Intention." Peabody Journal of Education, Fall 1985.

Shieve, L. T., and Shoenheit, M. B. "Vision and the Work Life of Educational Leaders." In Leadership: Examining the Elusive, edited by L. T. Shieve and M. B. Shoenheit. Washington, D.C.: Association for Supervision and Curriculum Development, 1987.

U.S. Department of Education. Principal Selection Guide. Washington, D.C.: U.S. Department of Education, 1987.

\section{Reading and Writing in the Schools}

The results of the National Center for Education Statistics' National Assessment Report reveal that: - High school females have higher reading and writing proficiencies than males

- Students attending schools in advantaged urban areas performed considerably better than those attending school in disadvantaged urban areas

- Students in the Southeast performed less well than those in the Northeast, West, and Central regions

- Home attention to literacy, including more reading materials in the home and higher levels of parental education, was positively related to proficiency. 